\title{
Prevalence of exclusive breastfeeding practice in the first six months of life and its determinants in Iran: a systematic review and meta-analysis
}

\author{
Meysam Behzadifar ${ }^{1}$, Mandana Saki ${ }^{1}$, Masoud Behzadifar ${ }^{2 *}$ (D, Mahnaz Mardani ${ }^{3}$, Fatemeh Yari ${ }^{4}$,
} Farzad Ebrahimzadeh ${ }^{5}$, Hadis Majidi Mehr ${ }^{6}$, Shadi Abdi Bastami ${ }^{6}$ and Nicola Luigi Bragazzi ${ }^{7}$

\begin{abstract}
Background: Exclusive breastfeeding (EBF) in the first 6 months of life is the best and most complete option for an infant, in that supplies the vitamins and minerals the baby needs. Several studies in Iran have been conducted concerning the prevalence of EBF. The aim of this study was to determine the prevalence of EBF in the first 6 months of life and associated factors in Iran synthesizing published studies.

Methods: We searched PubMed/MEDLINE, Embase, Scopus, ISI/Web of Science, the Cochrane Library, Directory of Open Access Journals Directory (DOAJ) and Google Scholar as well as Iranian databases (Barakathns, Maglran and the Scientific Information Database or SID) up to November 2018. The Newcastle-Ottawa Scale was used to assess the quality of studies. Analyses were performed by pooling together studies using DerSimonian-Laird randomeffects model with 95\% confidence interval. To test for heterogeneity, $I^{2}$ test was used. The Egger's regression test and funnel plot were used to evaluate the publication bias. The strength of EBF determinants was assessed computing the Odds-ratios (OR) using the Mantel-Haenszel method.
\end{abstract}

Results: In the initial search 725 records were found. Finally, 32 studies were selected based on inclusion/exclusion criteria. The sample size of studies varied between 50 and 63,071 subjects. The overall prevalence of EBF in Iran was 53\% (CI 95\%; 44-62). The OR for breastfeeding education received before pregnancy was 1.13 (0.94-1.36), for mother's job 1.01 (0.81-1.27), for education level 1.12 (0.89-1.42), for type of delivery $1.16(0.98-1.37)$, and for gender of child $1.03(0.83-1.28)$.

Conclusion: In Iran health policy- and decision-makers should try to take interventions that encourage mothers to use their milk to breastfeed the infants.

Keywords: Prevalence, Exclusive breastfeeding, Iran, Systematic review, Meta-analysis

\section{Background}

Exclusive breastfeeding (EBF) in the first 6 months of life is known to be the most complete nutrient for a newborn, in that it provides all the energy, vitamins and minerals the baby needs $[1,2]$. As the World Health Organization (WHO), the American Academy of Pediatrics

\footnotetext{
* Correspondence: masoudbehzadifar@gmail.com;

behzadifar.m@tak.iums.ac.ir

${ }^{2}$ Health Management and Economics Research Center, Iran University of

Medical Sciences, Tehran, Iran

Full list of author information is available at the end of the article
}

(AAP) and the United Nations Children's Fund (UNICEF) emphasize, it is important for an infant to receive only breast milk up to the first 6 months of age, whereas, after the first 6 months, breast milk can be given in addition to other foods [2-4].

However, despite its importance and its clinical implications, both in developed and developing countries, the full implementation of EBF practice encounters some obstacles and barriers. As such, health policy- and decision-makers should pay particular attention to this issue, making their efforts to design ad hoc programs for EBF promotion [5].

(c) The Author(s). 2019 Open Access This article is distributed under the terms of the Creative Commons Attribution 4.0 International License (http://creativecommons.org/licenses/by/4.0/), which permits unrestricted use, distribution, and reproduction in any medium, provided you give appropriate credit to the original author(s) and the source, provide a link to the Creative Commons license, and indicate if changes were made. The Creative Commons Public Domain Dedication waiver (http://creativecommons.org/publicdomain/zero/1.0/) applies to the data made available in this article, unless otherwise stated. 
The best cost-effective intervention to reduce mortality in countries is, indeed, to increase compliance to EBF practice [6].

EBF, both in the short and long term, has many benefits for the infant and the mother, which can curb the costs of infant care and nutrition, reduce the occurrence of several infectious diseases [7]. EBF is also effective in mitigating the burden of non-communicable diseases such as diabetes, asthma and cardiovascular disease in later years [8-10]. Despite the vast benefits of EBF, only half of infants under 1 month and about $30 \%$ of infants from 1 to 5 months are breastfed [11]. In studies conducted for estimating EBF prevalence and understanding its determinants, different factors have been individuated, including mother's awareness and positive attitude towards EBF, her socioeconomic and employment status, setting (urban versus rural areas), type of delivery, and weight of the baby at the time of birth [12-14].

The prevalence of EBF in the first 6 months of life in different countries has been explored. In a study conducted in a developing country (India), the prevalence was reported to be $34 \%$ [15]. Also, the prevalence rates of EBF in Turkey (38.9\%), in Tanzania (20.7\%), in Syria (12.9\%), and in Egypt (9.7\%) were reported [16-19]. Concerning prevalence of EBF in developed countries, in a study conducted in the United States, the rate was $16.8 \%$ [20]. The prevalence rates of EBF in other contests, including Spain (31.4\%), Canada (13.8\%) and Italy (5.5\%), were also documented [21-23].

Various studies have been conducted in Iran too, in order to evaluate the prevalence of EBF. Therefore, the aim of this study was to determine the prevalence of EBF and to study its determinants in Iran, summarizing the existing available investigations. The findings of this study can be helpful for health policy- and decisionmakers, planners, mothers, doctors, and all the other stakeholders in the field of healthcare in selecting effective interventions for the promotion of EBF practice.

\section{Methods}

The findings of this study were reported according to the "Preferred Reporting Items for Systematic Reviews and Meta-Analyzes" (PRISMA) Guidelines [24].

\section{Search strategy}

We searched different scholarly electronic databases, namely PubMed/MEDLINE, Embase, Scopus, ISI/Web of Science, the Cochrane Library, Directory of Open Access Journals Directory (DOAJ) and Google Scholar as well as Iranian databases (Barakathns, MagIran and the Scientific Information Database, SID) up to November 2018. The search terms used were: ("exclusive breastfeeding" OR "breastfeeding" OR "breast-feeding" OR "breastfeeding patterns" OR "breastfeeding practices" OR "breastfeeding status" OR "feeding status") AND ("frequency" OR "epidemiology" OR "prevalence" OR "patterns" OR "assessment" OR "investigation") AND "Iran". The reference list of included studies was also scanned in order to obtain relevant additional studies. A search strategy adapted to PubMed/MEDLINE, Scopus, ISI/ Web of Science and Embase is reported in appendix (Additional file 1).

\section{Inclusion criteria}

Inclusion criteria were: 1) studies in which mothers used their milk to feed their infants up to 6 months of age; 2) studies reporting the prevalence of EBF in the first 6 months of life; 3) studies in which babies were aged more than 6 months; 4 ) studies whose data were sufficient to calculate the prevalence; 5) studies published in peer-reviewed journals; and 6) studies written either in Persian or English.

\section{Exclusion criteria}

Exclusion criteria were the following: 1) studies designed as case-series, case-reports, randomized clinical trials, or interventional investigations; 2) studies whose data were inadequate or insufficient to estimate the prevalence of EBF; and 3) studies unavailable in full-text.

\section{Outcome measurement}

The outcomes of interest of this study included: 1) the prevalence of EBF practice in the first 6 months of life in Iranian children; and 2) the determinants of EBF practice.

\section{Data extraction}

We extracted the following data from the studies included in the present systematic review and meta-analysis: first author, year of publication, location, sample size, number of breastfed children, mothers' age, reported prevalence, determinants of EBF, study design, and language of study.

\section{Quality assessment (risk of bias)}

The Newcastle-Ottawa Scale (NOS) was used to assess the quality of studies. This tool consists of three major sections, concerning the methodological quality, the comparability and the outcomes and statistical analysis of each included study. Two authors independently critically appraised the quality of each original study using the NOS tool. Disagreements between the two authors were resolved by consensus. According to the stars assigned to each part, the studies with at least 5 stars out of 10 were considered of good quality [25].

To extract relevant data and to evaluate the quality of the studies, two authors independently performed these steps. In case of disagreement, consensus was reached through discussion. Kappa statistics was used to assess the agreement between the two authors. Kappa coefficient 
was 0.93 for data extraction and 0.81 for evaluation of study quality.

\section{Statistical analysis}

All analyses were conducted using Stata Version 12 (Stata Corp, College Station, TX, USA) utilizing the "metaprop" command [26]. Overall pooled estimates with inversevariance weights analyses were performed by logisticnormal random-effects model using DerSimonian-Laird approach with 95\% confidence interval (CI) [27]. In order to stabilize the variance the double arcsine transformation method according to Freeman and Tukey was used [28].

To test for heterogeneity, $\mathrm{I}^{2}$ test was utilized [29]. Subgroup analyses were conducted based on the sample size, the geographical area, and other variables such as education concerning EBF received before/during pregnancy, mother's job, education level, type of delivery, gender of child, birth weight, mother's diseases/co-morbidities and location of delivery. The Egger's linear regression test and the funnel plot were used to evaluate the publication bias [30]. To determine possible sources of heterogeneity, meta-regressions were carried out based on the year and the sample size of the studies. Also, sensitivity analysis was performed to check the stability of results. To assess the strength of the different determinants of
EBF practice, odds Ratio (OR) with its $95 \%$ CI was calculated using the Mantel-Haenszel method.

In all the statistical analyses, figures with a $p$-value less than 0.05 were considered statistically significant.

\section{Results}

\section{Findings of the search strategy}

In the initial search, 725 records were found. After removing duplicates, the title of 596 records was checked and 543 records were deleted. The abstract of 53 studies was then reviewed and, finally, the full text of 32 studies was selected based on inclusion/exclusion criteria. Figure 1 shows the process of the search and selection of studies.

\section{Main characteristics of included studies}

Selected studies were conducted between 2003 and 2015 [31-62]. The sample size of studies varied between 50 and 63,071 subjects. The main characteristics of retained studies are presented in Table 1.

\section{Findings of the quality assessment}

According to the NOS tool, the quality assessment showed that 4 studies were scored 6 stars, 9 studies 7 stars, 14 studies 8 stars, and 5 studies 9 stars. No study was excluded after rating because the study quality was

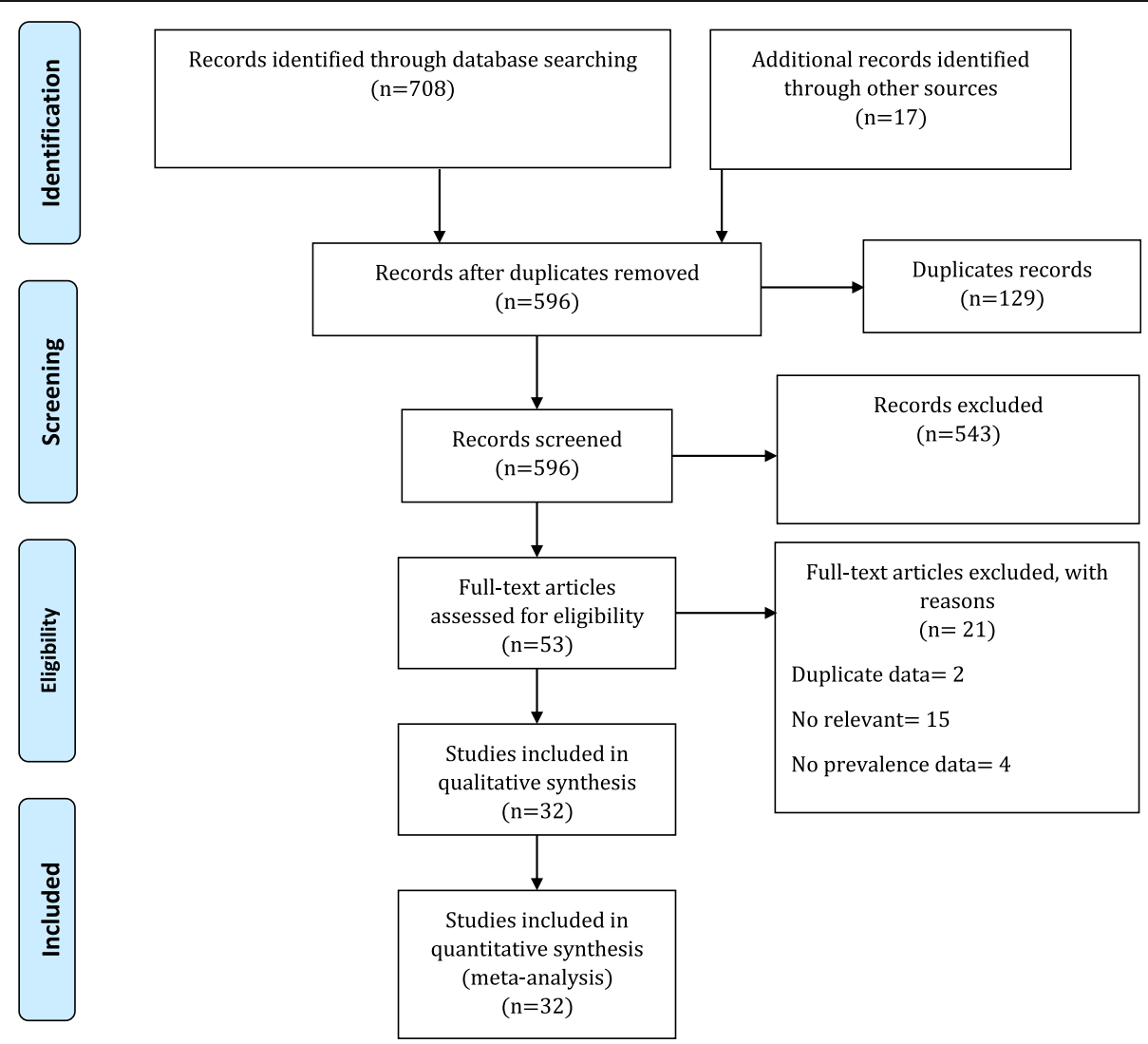

Fig. 1 Flowchart illustrating the process of search and selection of studies included in the present systematic review and meta-analysis 
Table 1 The characteristics of studies included

\begin{tabular}{|c|c|c|c|c|c|c|c|c|}
\hline First author & References & $\begin{array}{l}\text { Year of } \\
\text { publication }\end{array}$ & Region & $\begin{array}{l}\text { Age of mothers } \\
\text { (Mean } \pm \text { SD) }\end{array}$ & $\begin{array}{l}\text { Age of baby } \\
\text { (month) }\end{array}$ & $\begin{array}{l}\text { Sample } \\
\text { size }\end{array}$ & Study design & $\begin{array}{l}\text { Quality rating of } \\
\text { the studies (Stars) } \\
\text { (risk of bias) }\end{array}$ \\
\hline Imani & 31 & 2003 & Zahedan & NA & $6-24$ & 253 & Cross-sectional & 6 stars \\
\hline Hajian-Tilaki & 32 & 2005 & Babol & NA & 6 & 600 & Cross-sectional & 8 stars \\
\hline khabazkhoob & 33 & 2008 & Mashhad & NA & $7-12$ & 1267 & Cross-sectional & 7 stars \\
\hline Koosha & 34 & 2008 & Zanjan & NA & 12 & 50 & Cross-sectional & 6 stars \\
\hline Mohsenzadeh & 35 & 2008 & Khorramabad & NA & 12 & 340 & Cross-sectional & 8 stars \\
\hline Mohammad Beygi & 36 & 2009 & Arak & NA & $6-12$ & 352 & Cross-sectional & 9 stars \\
\hline Olang & 37 & 2009 & 30 provinces & NA & $<24$ & 63,071 & Retrospective & 8 stars \\
\hline Roudbari & 38 & 2009 & Zahedan & $25.5 \pm 6.2$ & 12 & 450 & Cross-sectional & 7 stars \\
\hline Almasi & 39 & 2010 & Kashan & NA & 6 & 391 & Cross-sectional & 8 stars \\
\hline Vafaee & 40 & 2010 & Mashhad & NA & 12 & 1450 & Cross-sectional & 9 stars \\
\hline Hamidi & 41 & 2011 & $\begin{array}{l}\text { Charmahalva } \\
\text { Bakhtiari }\end{array}$ & $29.25 \pm 5.5$ & $<12$ & 411 & $\begin{array}{l}\text { Descriptive- } \\
\text { analytical }\end{array}$ & 7 stars \\
\hline Mehrparvar & 42 & 2011 & Kerman & NA & $<12$ & 320 & Cross-sectional & 7 stars \\
\hline Naserpoor & 43 & 2011 & Omidieh & $27.5 \pm 5.5$ & $6-18$ & 400 & $\begin{array}{l}\text { Descriptive- } \\
\text { analytical }\end{array}$ & 8 stars \\
\hline Rahmatnejad & 44 & 2011 & Tehran & NA & 12 & 331 & Cross-sectional & 8 stars \\
\hline Torabi & 45 & 2011 & Jahrom & $28.1 \pm 5.36$ & $18-24$ & 435 & Cross-sectional & 7 stars \\
\hline Veghari & 46 & 2011 & Golestan & NA & $6-60$ & 2520 & Cross-sectional & 8 stars \\
\hline Yaghini & 47 & 2011 & Isfahan & NA & 12 & 656 & $\begin{array}{l}\text { Descriptive- } \\
\text { analytical }\end{array}$ & 6 stars \\
\hline Kermani & 48 & 2012 & Tehran & NA & 6 & 110 & Cross-sectional & 9 stars \\
\hline Mirahmadizadeh & 49 & 2012 & Shiraz & NA & $6-12$ & 751 & $\begin{array}{l}\text { Historical } \\
\text { cohort }\end{array}$ & 8 stars \\
\hline Morowatisharifabad & 50 & 2012 & Ardakan & NA & $6-12$ & 413 & Cross-sectional & 8 stars \\
\hline Ziaie & 51 & 2012 & Rasht & $30.93 \pm 4.801$ & $<12$ & 263 & $\begin{array}{l}\text { Descriptive- } \\
\text { analytical }\end{array}$ & 7 stars \\
\hline Charkazi & 52 & 2013 & Isfahan & $27.79+4.7$ & $6-24$ & 406 & Cross-sectional & 8 stars \\
\hline Kamali & 53 & 2013 & Tehran & $28.9 \pm 4.6$ & $12-24$ & 300 & Cross-sectional & 6 stars \\
\hline Khamnian & 54 & 2013 & East Azerbaijan & NA & 12 & 750 & Cross-sectional & 8 stars \\
\hline Saki & 55 & 2013 & Shiraz & NA & 12 & 287 & $\begin{array}{l}\text { Prospective } \\
\text { follow-up }\end{array}$ & 7 stars \\
\hline Abdollahi & 56 & 2014 & Sari & $27.99 \pm 4.7$ & $<12$ & 400 & Cross-sectional & 9 stars \\
\hline Aghababaii & 57 & 2014 & Hamadan & $26.7 \pm 4.8$ & 12 & 1200 & Cross-sectional & 8 stars \\
\hline Dalili & 58 & 2014 & Tehran & NA & 6 & 175 & Cross-sectional & 7 stars \\
\hline Ghanbarnejad & 59 & 2014 & Bandar Abbas & $25.7 \pm 5.6$ & 6 & 800 & Cross-sectional & 7 stars \\
\hline Noughabi & 60 & 2014 & Tehran & NA & $6-24$ & 538 & Cross-sectional & 8 stars \\
\hline Ranjbaran & 61 & 2014 & Shazand & NA & 6 & 283 & Cross-sectional & 8 stars \\
\hline Roostaee & 62 & 2015 & Zahedan & NA & 12 & 523 & Cross-sectional & 9 stars \\
\hline
\end{tabular}

always above 5 stars. Result of assessment of risk of bias for each study are reported in Table 1 .

\section{Findings of the meta-analysis}

Based on DerSimonian-Laird model, EBF prevalence in Iran was computed to be 53\% (CI 95\%; 44-62) (Fig. 2). Heterogeneity resulted statistically high, $\mathrm{I}^{2}=99.7 \%, P=$
0.000. Sensitivity analysis also showed that the results did not change before and after the analysis and confirmed the stability of the results.

\section{Findings of the subgroup analysis}

Table 2 shows the results of the subgroup analysis. According to the geographical area of the study, the highest 


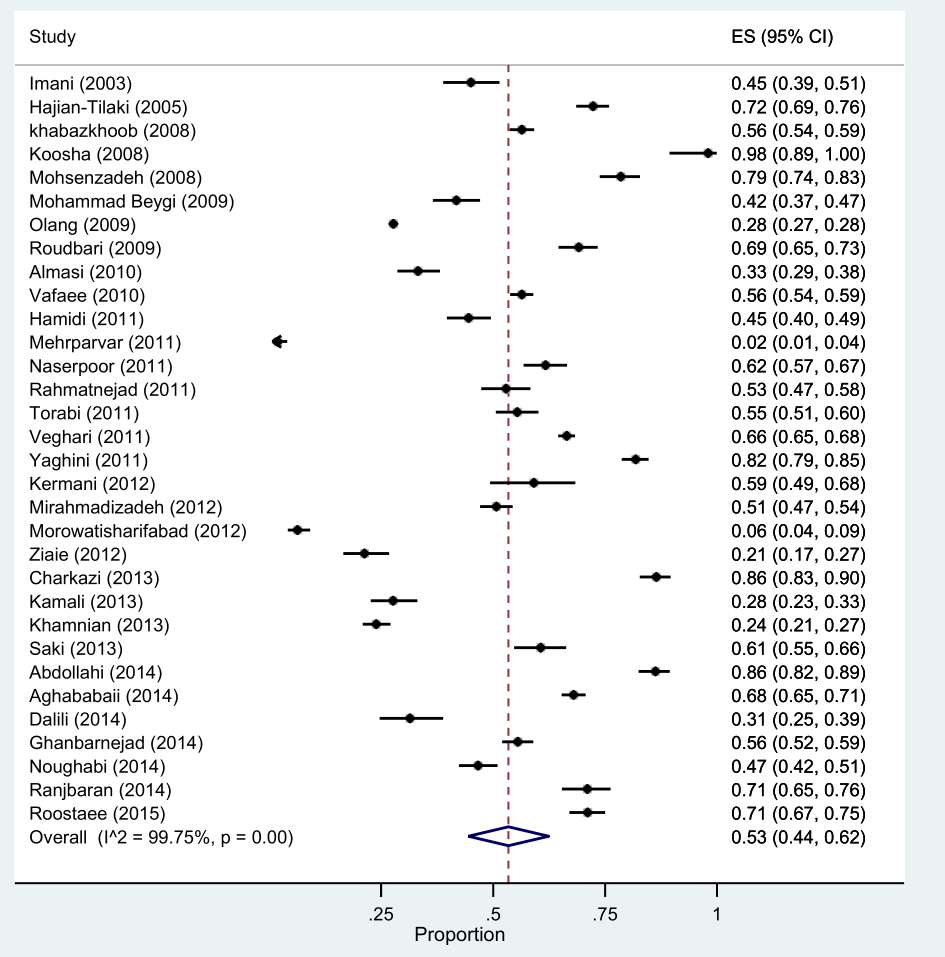

Fig. 2 The overall prevalence of EBF in Iran

prevalence of EBF was observed in the north (62\% versus $61 \%$ in the west, $60 \%$ in the east, $48 \%$ in the south, and $47 \%$ in the center of Iran). In terms of sample size, in studies with a sample size comprising more than 500 subjects, the prevalence was $56 \%$, and $52 \%$ in studies with less than or equal to 500 individuals. The prevalence of EBF in mothers who had been educated before and during pregnancy was $55 \%$ and $50 \%$, respectively. The prevalence of EBF in unemployed and employed mothers was $58 \%$ and $55 \%$, respectively. In terms of educational level, the prevalence of EBF in mothers without and with higher education was $58 \%$ and $56 \%$, respectively. The prevalence of EBF in mothers who delivered vaginally was $58 \%$ and $49 \%$ in mothers who underwent cesarean section. The prevalence of EBF stratified according to the gender of baby was $60 \%$ and $50 \%$ in case of female and male, respectively. The prevalence of EBF in infants weighing less than $2500 \mathrm{~g}$ was $62 \%$ while was $60 \%$ in infants weighing more than $2500 \mathrm{~g}$. In mothers with diabetes, kidney, and cardiovascular disease, the prevalence of EBF was 44\%, while it was $50 \%$ in healthy mothers. The prevalence of EBF in mothers giving birth at government hospitals was $69 \%$ and $51 \%$ in mothers who delivered their babies in private hospitals.

\section{Determinants of exclusive breastfeeding in Iran}

Association between some variables and prevalence of EBF was considered in Table 3. In this table, the strengths of the determinants of EBF practice based on the OR computed according to the Mantel-Haenszel method are reported. More in detail, the OR for breastfeeding education received before pregnancy was $1.13(0.94-1.36)$, for mother's job 1.01 (0.81-1.27), for education level 1.12 (0.89-1.42), for type of delivery $1.16(0.98-1.37)$, and for gender of child $1.03(0.83-1.28)$. All of these predictors were not statistically significant, even though suggestive of a trend.

\section{Findings of the meta-regressions}

Meta-regressions were performed based on the year of publication and the sample size; the results are shown in Table 4. Based on the year of publication $(P=0.61)$ and the sample size $(P=0.26)$ of included studies, EBF exhibits a decreasing trend throughout the time, even though not statistically significant.

\section{Publication bias}

Using the Egger's linear regression test, the publication bias of included studies was investigated, and resulted 
Table 2 The results of subgroup-analyses

\begin{tabular}{|c|c|c|c|c|}
\hline \multirow[t]{2}{*}{ Variables } & \multirow{2}{*}{$\begin{array}{l}\text { Number of } \\
\text { studies }\end{array}$} & \multirow{2}{*}{$\begin{array}{l}\text { Prevalence } \\
(95 \% \text { Cl) }\end{array}$} & \multicolumn{2}{|c|}{ Heterogeneity } \\
\hline & & & $1^{2}$ & $P$-Value \\
\hline \multicolumn{5}{|l|}{ Geographical region } \\
\hline North & 4 & $62 \%(42-81)$ & $99.4 \%$ & 0.000 \\
\hline South & 6 & $48 \%(20-75)$ & $99.7 \%$ & 0.000 \\
\hline West & 7 & $61 \%(41-81)$ & $99.5 \%$ & 0.000 \\
\hline East & 5 & $60 \%(52-67)$ & $95.3 \%$ & 0.000 \\
\hline Center & 9 & $47 \%(24-70)$ & $99.7 \%$ & 0.000 \\
\hline \multicolumn{5}{|l|}{ Sample size } \\
\hline$\leq 500$ & 20 & $52 \%(35-68)$ & $99.7 \%$ & 0.000 \\
\hline$>500$ & 12 & $56 \%(42-70)$ & $99.8 \%$ & 0.000 \\
\hline \multicolumn{5}{|c|}{ Education before pregnancy } \\
\hline Yes & 6 & $55 \%(39-71)$ & $98.4 \%$ & 0.000 \\
\hline No & 6 & $50 \%(35-64)$ & $88.5 \%$ & 0.000 \\
\hline \multicolumn{5}{|c|}{ Maternal employment } \\
\hline Unemployed & 6 & $58 \%(46-69)$ & $95.8 \%$ & 0.000 \\
\hline Employed & 6 & $55 \%(37-73)$ & $92.9 \%$ & 0.000 \\
\hline Education level & & & & 0.000 \\
\hline Under diploma & 6 & $58 \%(51-64)$ & $52.4 \%$ & 0.000 \\
\hline Upper diploma & 6 & $56 \%(42-69)$ & $97.3 \%$ & 0.000 \\
\hline Type of delivery & & & & 0.000 \\
\hline Vagina & 5 & $58 \%(43-74)$ & $97.1 \%$ & 0.000 \\
\hline Cesarian & 5 & $49 \%(34-64)$ & $95.7 \%$ & 0.000 \\
\hline Gender of child & & & & 0.000 \\
\hline Girl & 4 & $60 \%(40-80)$ & $97.6 \%$ & 0.000 \\
\hline Boy & 4 & $59 \%(41-78)$ & $96.8 \%$ & 0.000 \\
\hline Birth weight & & & & 0.000 \\
\hline Under $2500 \mathrm{~g}$ & 3 & $62 \%(54-70)$ & $0 \%$ & 0.000 \\
\hline Upper $2500 \mathrm{~g}$ & 3 & $60 \%(40-80)$ & $97.8 \%$ & 0.000 \\
\hline \multicolumn{4}{|c|}{ Mother with history of diseases (Diabetes, hypertension, ...) } & 0.000 \\
\hline Yes & 2 & $44 \%(20-68)$ & $86.6 \%$ & 0.000 \\
\hline No & 2 & $50 \%(24-76)$ & $85.7 \%$ & 0.000 \\
\hline \multicolumn{4}{|l|}{ Location of delivery } & 0.000 \\
\hline Govermental & 2 & $69 \%(45-93)$ & $97.5 \%$ & 0.000 \\
\hline Private & 2 & $51 \%(34-71)$ & $98.6 \%$ & 0.000 \\
\hline
\end{tabular}

not statistically significant $(P=0.27)$, as pictorially shown in Fig. 3.

\section{Discussion}

The aim of this study was to investigate the prevalence of EBF practice in the first 6 months of life in Iran synthesizing available published studies.

\section{Determinants of exclusive breastfeeding in Iran}

In this systematic review and meta-analysis, based on the data from included studies, we examined the determinants
Table 3 Odds-ratios for the different determinants of EBF practice

\begin{tabular}{|c|c|c|c|c|}
\hline Variables & $\begin{array}{l}\text { Number of } \\
\text { studies }\end{array}$ & $\begin{array}{l}\text { Odds ratio } \\
(95 \% \mathrm{Cl})\end{array}$ & $\mathrm{I}^{2}$ & $P$-Value \\
\hline $\begin{array}{l}\text { Education concerning } \\
\text { breastfeeding received } \\
\text { before pregnancy }\end{array}$ & 6 & $1.13(0.94-1.36)$ & $0 \%$ & 0.93 \\
\hline Mother's job & 6 & $1.01(0.81-1.27)$ & $0 \%$ & 0.60 \\
\hline Education level & 6 & $1.12(0.89-1.42)$ & $25.2 \%$ & 0.24 \\
\hline Type of delivery & 5 & $1.16(0.98-1.37)$ & $21.1 \%$ & 0.28 \\
\hline Gender of child & 4 & $1.03(0.83-1.28)$ & $39.1 \%$ & 0.17 \\
\hline Birth weight & 3 & $1.15(0.86-1.55)$ & $0 \%$ & 0.43 \\
\hline $\begin{array}{l}\text { Mother with history } \\
\text { of diseases (Diabetes, } \\
\text { hypertension, ...) }\end{array}$ & 2 & $0.94(0.58-1.52)$ & $0 \%$ & 0.96 \\
\hline Location of delivery & 2 & $1.32(0.56-3.11)$ & $78.8 \%$ & 0.03 \\
\hline
\end{tabular}

of EBF. Training received before and during pregnancy can have an impact on the three dimensions of knowledge, attitudes and behavior of the mothers and encourage them to practice EBF [63]. The findings of this study showed, indeed, that EBF in mothers who received training was higher than in untrained mothers.

Pregnant women and their spouses should be carefully informed about infant birth and breastfeeding, an integral part of prenatal care. Other members of the family who can support breastfeeding can be trained too [64]. Training can be done at health centers and clinics. Hospitals and other institutions can also provide training for pregnant women and their partners. Other health system staff, such as pediatricians, nurses and midwives, play an important role, as well as mother-to-mother education groups and other organizations [65].

Maternal occupation was one of the factors contributing to an increase in the prevalence of EBF. The findings of this study showed that the prevalence of EBF in Iranian housewife mothers was higher than that of employed mothers. This finding is consistent with the results of studies carried out in Ethiopia [66], Saudi Arabia [67], Canada [22] and Jordan [68].

Mothers who work suffer from lack of time, and fatigue, and may find difficulties in breastfeeding [69]. Employment regulations play an important role in promoting EBF practice, by giving mothers more time to breastfeed their babies [70]. On the other hand, it seems that postpartum leave is more likely to lead to an increase in EBF. As such, postpartum mothers need more support from their employers [71].

At present, women in Iran can use 6 months of maternity leave, and their husbands can use 2 weeks. This law is better enforced in governmental organizations but not in many nongovernmental organizations. Although policy- 
Table 4 The results of meta-regressions

\begin{tabular}{lllllll}
\hline Variables & Coefficient & SE & T & $P$-Value & Cl 95\% Lower & Cl 95\% Upper \\
\hline Year of publication & -0.00 & 0.01 & -0.51 & 0.61 & -0.03 & 0.02 \\
Sample size & -4.41 & 3.8 & -1.15 & 0.26 & -0.00 & 3.44 \\
Constant & 16.48 & 31.46 & 0.52 & 0.60 & -47.86 & 80.82 \\
\hline
\end{tabular}

and decision-makers are making a lot of efforts to increase the application of this law, they still have problems such as lack of support from insurance organizations, from employers, and lack of sufficient funding [72].

The findings of this study showed that the prevalence of EBF in less literate women is higher than that of women with university education, which is consistent with findings from studies conducted in Bangladesh [5], United Arab Emirates [73] and Ethiopia [74]. Mothers with lower education appear to be more interested in EBF education. Maternal education is recognized as an important social component for promotion and healthcare of children [75]. In a systematic review carried out in high-income countries, results showed that interventions designed and implemented for educational purposes significantly increased the practice of EBF [76].

In our study, the findings showed that the prevalence of EBF in women who gave birth vaginally was higher than that of mothers who had cesarean section, which is consistent with the results of studies performed in Ecuador [77], Saudi Arabia [78], and Jordan [68]. The results of a meta-analysis of 53 studies showed that EBF rates were lower in women with cesarean delivery than in women with vaginal delivery [79]. Health-care providers should increase the awareness of women concerning delivery. Cesarean section is, indeed, associated with special surgical procedures and the use of local anesthesia. It is characterized by a high probability of uterine or urinary infections, increased bleeding, constipation, increased hospitalization time, and higher economic costs [80]. The results of a study showed that women who had cesarean section had a greater tendency to do so in later pregnancies and, accordingly, increased their EBF levels compared to their previous one [81].

According to a meta-analysis, the prevalence of cesarean section in Iran was estimated to be $48 \%$ [82]. This rate is rather higher when compared to other countries. Since cesarean delivery can have negative effects on the mother and the baby, such as EBF reduction, health policy- and decision-makers in Iran should make a lot of effort to reduce the use of cesarean delivery [83]. In the Health System Transformation Plan (HSTP), which began in 2014 in Iran, much attention has been paid to reducing cesarean delivery in Iran, and health-care service providers pay for maternity welfare costs to mothers to reduce this kind of delivery [84].

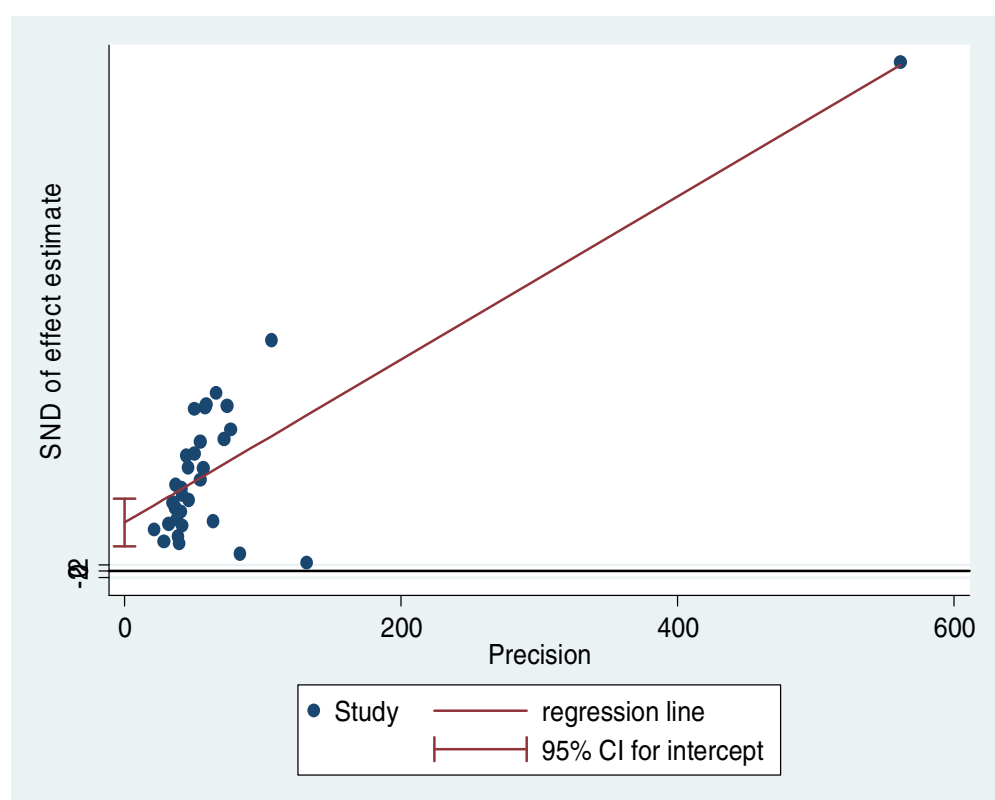

Fig. 3 The results of the publication bias analysis based on the Egger's linear regression test and the visual inspection of the funnel plot 
In the present study, the prevalence of EBF in mothers with male children was higher compared to mother with female infants and this is consistent with the results of a study conducted in Saudi Arabia [78] and the findings of study performed in Ghana [85].

Based on the results of our study, the prevalence of EBF in infants whose birth weight was less than $2500 \mathrm{~g}$ was higher than that of infants above this weight. Infants with low birth weight are at risk for certain diseases. Breast milk can improve the function of the digestive system, reducing infections [86]. Studies have shown that EBF is a necessity for infants weighing less than $2500 \mathrm{~g}$ and should be taken seriously by mothers $[87,88]$.

Health policy- and decision-makers in Iran have always emphasized the importance and the benefits of EBF and, given its religious, social and economic implications, have implemented broad programs for education and promotion at the community level. Appropriate laws have been approved to promote EBF and supporting mothers during lactation in recent years. In 2011, the maternity leave law was approved for mothers who breastfeed their babies, and according to that, employers can extend maternity leave for a period of 9 months, and the period of maternity leave for triple or more childbirths (1 year receiving salaries). Also, these mothers can come to work $1 \mathrm{~h}$ later or leave the workplace $1 \mathrm{~h}$ earlier. All government agencies are required to provide female employees with appropriate facilities enabling EBF at the workplace. This law focuses on protecting working women and ensuring their job security, taking into account the specific circumstances of women in lactation, as well as on improving the condition of the growth of their infants.

\section{Strengths and limitations}

Comprehensive search of various scholarly databases, sub-group analysis, meta-regressions and sensitivity analysis were among the strengths of this systematic review and meta-analysis. However, this study also had some limitations, which should be properly recognized. In some Iranian studies, there was no study on the prevalence of EBF. Methodological differences in studies may have led to a high, statistically significant heterogeneity. Low sample size of many studies (21 studies with a sample size less than 500) represents another limitation of the present investigation.

\section{Conclusion}

Our findings indicate that EBF prevalence in Iran was $53 \%$. Undoubtedly, the use of breast milk has many benefits for the baby, and, as such, policy- and decision-makers in the health sector should try to improve maternal care by improving care during pregnancy and after childbirth, giving more education to their mother and their families.

\section{Supplementary information}

Supplementary information accompanies this paper at https://doi.org/10. 1186/s12887-019-1776-0.

Additional file 1. Search strategy in PubMed/MEDLINE, Scopus, ISI/Web of Science and Embase databases. Description of data: Details of the search strategy.

\begin{abstract}
Abbreviations
AAP: American Academy of Pediatrics; Cl: Confidence Interval; EBF: Exclusive breastfeeding; EMRO: Eastern Mediterranean Regional Office; OR: Odds Ratio; PRISMA: Preferred Reporting Items for Systematic Reviews and MetaAnalyzes; SID: Scientific Information Database; UNICEF: United Nations Children's Fund; WHO: World Health Organization
\end{abstract}

\section{Acknowledgements}

This study was supported by the Social Determinants of Health Research Center, Lorestan.

University of Medical Sciences.

\section{Authors' contributions}

MS, MeB and MaB designed the study. HMM, SAB and MaB searched databases, extracted data and performed study selection. MaB and NLB performed data analysis. FY, MM, MeB, NLB, MS and MaB interpreted the results. $M a B$ and $M e B$ wrote the manuscript. MS, FY, and FE have been involved in drafting the manuscript or revising it critically for important intellectual content. MaB, MeB, FY, MS, MM and NLB carried out a final revision and grammar editing. All authors read and approved the final manuscript.

\section{Funding}

Not applicable.

\section{Availability of data and materials}

Not applicable.

Ethics approval and consent to participate

Not applicable.

\section{Consent for publication}

Not applicable.

\section{Competing interests}

The authors declare that they have no competing interests.

\section{Author details}

'Social Determinants of Health Research Center, Lorestan University of Medical Sciences, Khorramabad, Iran. ${ }^{2}$ Health Management and Economics Research Center, Iran University of Medical Sciences, Tehran, Iran. ${ }^{3}$ Nutritional Health Research Center, Lorestan University of Medical Sciences, Khorramabad, Iran. ${ }^{4}$ Department of Midwifery, Faculty of Nursing and Midwifery, Lorestan University of Medical Sciences, Khorrmabad, Iran. ${ }^{5}$ Department of Biostatistics, School of Health and Nutrition, Lorestan University of Medical Sciences, Khorramabad, Iran. ${ }^{6}$ Department of Public Health, Faculty of Health and Nutrition, Lorestan University of Medical Sciences, Khorramabad, Iran. ${ }^{7}$ School of Public Health, Department of Health Sciences (DISSAL), University of Genoa, Genoa, Italy.

Received: 16 December 2018 Accepted: 9 October 2019

Published online: 27 October 2019

References

1. Khayat S, Fanaei H, Ghanbarzehi A. Minerals in pregnancy and lactation: a review article. J Clin Diagn Res. 2017;11(9):QE01-QE5.

2. Butte NF, Lopez-Alarcon MG, Garza C. Nutrient adequacy of exclusive breastfeeding for the term infant during the first six months of life. Geneva: World Health Organization; 2002.

3. Gartner LM, Morton J, Lawrence RA, Naylor AJ, O'Hare D, Schanler RJ, et al. Breastfeeding and the use of human milk. Pediatrics. 2005;115(2):496-506. 
4. World Health Organization: UNICEF. Global strategy for infant and young child feeding 2003 [Available from: http://www.who.int/nutrition/ publications/infantfeeding/9241562218/en/. Accessed 16 Dec 2018.

5. Joshi PC, Angdembe MR, Das SK, Ahmed S, Faruque ASG, Ahmed T. Prevalence of exclusive breastfeeding and associated factors among mothers in rural Bangladesh: a cross-sectional study. Int Breastfeed J. 2014:9:7.

6. Fjeld E, Siziya S, Katepa-Bwalya M, Kankasa C, Moland KM, Tylleskär T. PROMISE-EBF Study Group. 'No sister, the breast alone is not enough for my baby' a qualitative assessment of potentials and barriers in the promotion of exclusive breastfeeding in southern Zambia. Int Breastfeed J. 2008;3:26.

7. Henrick BM, Yao X-D, Nasser L, Roozrogousheh A, Rosenthal KL. Breastfeeding behaviors and the innate immune system of human milk: working together to protect infants against inflammation, HIV-1, and other infections. Front Immunol. 2017:8:1631.

8. Owen CG, Whincup PH, Cook DG. Breast-feeding and cardiovascular risk factors and outcomes in later life: evidence from epidemiological studies. Proc Nutr Soc. 2011;70(4):478-84.

9. Bagci Bosi AT, Eriksen KG, Sobko T, Wijnhoven TM, Breda J. Breastfeeding practices and policies in WHO European region member states. Public Health Nutr. 2016;19(4):753-64.

10. Gouveri E, Papanas N, Hatzitolios Al, Maltezos E. Breastfeeding and diabetes. Curr Diabetes Rev. 2011;7(2):135-42.

11. Black RE, Victora CG, Walker SP, Bhutta ZA, Christian P, de Onis M, et al. Maternal and child undernutrition and overweight in low-income and middle-income countries. Lancet. 2013;382(9890):427-51.

12. Hector D, King L, Webb K, Heywood P. Factors affecting breastfeeding practices: applying a conceptual framework. N S W Public Health Bull. 2005; 16(3-4):52-5.

13. Huang $P$, Ren J, Liu Y, Luo B, Zhao X. Factors affecting breastfeeding adherence among Chinese mothers: a multicenter study. Medicine (Baltimore). 2017;96(38):e7619.

14. Tavoulari E-F, Benetou V, Vlastarakos PV, Psaltopoulou T, Chrousos G, Kreatsas $G$, et al. Factors affecting breastfeeding duration in Greece: what is important? World J Clin Pediatr. 2016;5(3):349-57.

15. Radhakrishnan S, Balamuruga SS. Prevalence of exclusive breastfeeding practices among rural women in Tamil Nadu. Int J Health Allied Sci. 2012; 1(2):64-7.

16. Yılmaz E, Doğa Öcal F, Vural Yılmaz Z, Ceyhan M, Kara OF, Küçüközkan T. Early initiation and exclusive breastfeeding: factors influencing the attitudes of mothers who gave birth in a baby-friendly hospital. Turk J Obstet Gynecol. 2017;14(1):1-9.

17. Mgongo M, Mosha MV, Uriyo JG, Msuya SE, Stray-Pedersen B. Prevalence and predictors of exclusive breastfeeding among women in Kilimanjaro region, northern Tanzania: a population based cross-sectional study. Int Breastfeed J. 2013;8(1):12.

18. Al-Akour NA, Okour A, Aldebes RT. Factors associated with exclusive breastfeeding practices among mothers in Syria: a cross-sectional study. Br J Med Med Res. 2014;4(14):2713-24.

19. Al Ghwass MM, Ahmed D. Prevalence and predictors of 6-month exclusive breastfeeding in a rural area in Egypt. Breastfeed Med. 2011;6(4):191-6.

20. Jones JR, Kogan MD, Singh GK, Dee DL, Grummer-Strawn LM. Factors associated with exclusive breastfeeding in the United States. Pediatrics. 2011:128(6):1117-25.

21. Fernández-Cañadas Morillo $A$, Durán Duque M, Hernández López AB, Muriel Miguel C, Martínez Rodríguez B, Oscoz Prim A, et al. A comparison of factors associated with cessation of exclusive breastfeeding at 3 and 6 months. Breastfeed Med. 2017;12(7):430-5.

22. Al-Sahab B, Lanes A, Feldman M, Tamim H. Prevalence and predictors of 6 month exclusive breastfeeding among Canadian women: a national survey. BMC Pediatr. 2010;10:20

23. Lauria L, Spinelli A, Grandolfo M. Prevalence of breastfeeding in Italy: a population based follow-up study. Ann Ist Super Sanita. 2016;52(3):457-61.

24. Liberati A, Altman DG, Tetzlaff J, Mulrow C, Gotzsche PC, loannidis JP, et al The PRISMA statement for reporting systematic reviews and meta-analyses of studies that evaluate healthcare interventions: explanation and elaboration. BMJ. 2009:b2700:339.

25. Stang A. Critical evaluation of the Newcastle-Ottawa scale for the assessment of the quality of nonrandomized studies in meta-analyses. Eur J Epidemiol. 2010;25(9):603-5.

26. Nyaga VN, Arbyn M, Aerts M. Metaprop: a Stata command to perform metaanalysis of binomial data. Arch Public Health. 2014;72(1):39.
27. DerSimonian R, Laird N. Meta-analysis in clinical trials revisited. Contemp Clin Trials. 2015;45(Pt A):139-45.

28. Freeman MF, Tukey JW. Transformations related to the angular and the square root. Ann Math Stats. 1950;21(4):607-11.

29. Higgins JP, Thompson SG, Deeks JJ, Altman DG. Measuring inconsistency in meta-analyses. BMJ. 2003;327(7414):557-60.

30. Egger M, Davey Smith G, Schneider M, Minder C. Bias in meta-analysis detected by a simple, graphical test. BMJ. 1997:315(7109):629-34.

31. Imani M, Mohammadi M, Rakhshani F, Shafie S. Breast feeding and its related factors in Zahedan. Feyz. 2003;7(2):26-33.

32. Hajian-Tilaki KO. Factors associated with the pattern of breastfeeding in the north of Iran. Ann Hum Biol. 2005;32(6):702-13.

33. Khabazkhoob M, Fotouhi A, Majdi M, Moradi A, Javaherforoshzadeh A, Haer Kermani Z, et al. Prevalence of exclusive breastfeeding in health center Mashhad, 2007. IRJE. 2008:3(3 and 4):45-53.

34. Koosha A, Hashemifesharaki R, Mousavinasab N. Breast-feeding patterns and factors determining exclusive breast-feeding. Singap Med J. 2008:49(12):1002-6.

35. Mohsenzande A, Mardani M, Shahkarami K, Ebrahimzadeh F. FE failure of exclusive breast feeding in first 6 months of life of infants referred to health centers of Khorramabad. Yafte. 2008;10(1):54-62.

36. Mohammad Beygi A, Mohammad Salehy N, Bayati A. The pattern of exclusive breast feeding in referred neonatal to health centers of Arak. J Guilan Univ Med Sci. 2009:18(70):17-25.

37. Olang B, Farivar K, Heidarzadeh A, Strandvik B, Yngve A. Breastfeeding in Iran: prevalence, duration and current recommendations. Int Breastfeed J. 2009;4:8.

38. Roudbari M, Roudbari S, Fazaeli A. Factors associated with breastfeeding patterns in women who recourse to health centres in Zahedan, Iran. Singapore Med J. 2009;50(2):181-4

39. Almasi $H$, Saberi $H$, Moravveji SA. The pattern of exclusive breast feeding in neonates under healthcares in health centers of Kashan city during 2006. Feyz. 2010;14(2):163-8.

40. Vafaee A, Khabazkhoob M, Moradi A, Najafpoor A. Prevalence of exclusive breastfeeding during the first six months of life and its determinant factors on the referring children to the health centers in Mashhad, northeast of Iran-2007. J Appl Sci. 2010;10(4):343-8.

41. Hamidi M, Khoshdel A, Khadivi R, Deris F, Salehi-Fard A, Parvin N, et al. The causes of formula milk consumption in the infants under 1 year old in Charmahalva Bakhtiari provins Iran, 2007. J Shahrekord Univ Med Sci. 2011; 13(3):77-83.

42. Mehrparvar S, Varzandeh M. Investigation of decreasing causes of exclusive breastfeeding in children below six months old, in Kerman city during 2008-2009. J Fasa Univ Med Sci. 2011;1(1):45-52

43. Naserpoor F, Nouhjah S, Sharifat R. The pattern of exclusive breastfeeding and related factors in children referred to health centers of Omidieh city in 2010. Jentashapir J Health Res. 2011;2(3):118-24.

44. Rahmatnejad L, Bastani F. Factors associated with discotinuation of exclusive breast feeding by first time mothers. IJN. 2011;24(71):42-53.

45. Torabi S, Managheb S, Rahmanian S, Zahedi R, Solhjoo Z. Nutritional status of children under two years and its associated factors in urban and rural areas of Jahrom, 2007-8. JMJ. 2011:9(2):15-20.

46. Veghari G, Mansourian A, Abdollahi A. Breastfeeding status and some related factors in northern Iran. Oman Med J. 2011:26(5):342-8.

47. Yaghini SO, Khameh S, Danesh F, Modaresi MR, Saneian H. Determinants of exclusive breast milk feeding of infants in Isfahan, Iran. J Isfahan Med Sch. 2011;28(117):1126-39.

48. Kermani R, Nedaeifard L, Tehrani M, Nateghi MR, Fazeli A. Pattern of breastfeeding in infants conceived by assisted reproductive techniques at royan institute from birth to 6 months in Tehran - Iran. J Family Reprod Health. 2012;6(3):105-9.

49. Mirahmadizadeh A, Zare P, Moradi F, Sayadi M, Hesami E, Moghadami M. Exclusive breast-feeding weaning pattern and its determinant factors in Fars province in 2010. Daneshvar. 2012;19(99):11-22.

50. Morowatisharifabad M, Hajizadeh $\mathrm{H}$, Akhavan Karbasi S, Fallahzadeh $\mathrm{H}$ Study of the status of 6-12 months children exclusive breast-fed up to six months and its related factors in the urban health care centers of Ardakan city. J Shahid Sadoughi Univ Med Sci. 2012;40(3):64-94.

51. Ziaie T, Ghanbari A, Hassanzadeh Rad A, Yazdani MA. Investigating risk factors of failure in exclusive breastfeeding in less than one-year-old children referred to health centers in Rasht city. Iranian J Obstet Gynecol Infertil. 2012;15(18):32-9. 
52. Charkazi A, Miraeiz SZ, Razzaghnejad A, Shahnazi H, Hasanzadeh A, Badleh MT. Breastfeeding status during the first two years of infants' life and its risk factors based on BASNEF model structures in Isfahan. J Educ Health Promot. 2013;2:9.

53. Kamali Z, Rasouli B, Roodpeyma S, Haji Mirsadeghi Z, Eivani M. Assessment of breastfeeding and related factors in three hospitals of Tehran, 2008. Iranian J Nutr Sci Food Technol. 2013;7(5):125-34.

54. Khamnian Z, Azarfar A, Ravanshad Y, Hashemian M, Hasanpour K. Exclusive breastfeeding and factors affecting knowledge, attitude and practice of mothers in rural and urban regions of East Azerbaijan, Iran. Life Sci J. 2013; 10(5s):473-8.

55. Saki A, Eshraghian MR, Tabesh $H$. Patterns of daily duration and frequency of breastfeeding among exclusively breastfed infants in shiraz, Iran, a 6month follow-up study using bayesian generalized linear mixed models. Glob J Health Sci. 2013;5(2):123-33.

56. Abdollahi F, Charati JY, Roohani S. Exclusive breastfeeding by mothers attending primary health centers in sari, 2012. J Mazandaran Univ Med Sci. 2014;24(115):13-21.

57. Aghababaii S, Artimani T, Mahjoob H, Shobeiri F. Assessing the infant's breastfeeding in Hamadan city, Iran. SJMMS. 2014;2(10):86-91.

58. Dalili H, Farsar A, Barakati H, Raji F, Shariat M, Pourmalek F, et al. Frequency of exclusive breastfeeding and its affecting factors in Tehran, 2011. Acta Med Iran. 2014;52(7):552-6.

59. Ghanbarnejad A, Abedini S, Taqipoor L. Exclusive breastfeeding and its related factors among infants in Bandar Abbas city, Iran. J Babol Univ of Med Sci. 2014;16(1):85-91.

60. Noughabi Z, Tehrani GS, Foroushani A, Nayeri F, Baheiraei A. Prevalence and factors associated with exclusive breastfeeding at 6 months of life in Tehran: a population-based study. East Mediterr Health J. 2014;20(1):24-32.

61. Ranjbaran M, Jafari Manesh H, Panahi M, Baderan M, Shamsi M, Nakhaei M, et al. The survey of exclusive breast feeding and some socio-economical determinants in Shazand-Arak in 2014. J Health Community. 2014;8(2):10-9.

62. Roostaee F, Tabatabaei SM, Zaboli M, Keykhaie R, Sharifi-Rad J, Shahrak P, et al. Breast-feeding continuation in south-eastern of Iran: the associated factors. Med Arh. 2015;69(2):98-102.

63. Renfrew MJ, McCormick FM, Wade A, Quinn B, Dowswell T. Support for healthy breastfeeding mothers with healthy term babies. Cochrane Database Syst Rev. 2012;5:CD001141.

64. Mangasaryan N, Martin L, Brownlee A, Ogunlade A, Rudert C, Cai X. Breastfeeding promotion, support and protection: review of six country programmes. Nutrients. 2012;4(8):990-1014.

65. Samuel FO, Olaolorun FM, Adeniyi JD. A training intervention on child feeding among primary healthcare workers in Ibadan municipality. Afr J Prim Health Care Fam Med. 2016;8(1):884.

66. Chekol DA, Biks GA, Gelaw YA, Melsew YA. Exclusive breastfeeding and mothers' employment status in Gondar town, Northwest Ethiopia: a comparative cross-sectional study. Int Breastfeed J. 2017;12:27.

67. El-Gilany A-H, Shady E, Helal R. Exclusive breastfeeding in Al-Hassa, Saudi Arabia. Breastfeed Med. 2011;6(4):209-13.

68. Khasawneh $\mathbf{W}$, Khasawneh AA. Predictors and barriers to breastfeeding in north of Jordan: could we do better? Int Breastfeed J. 2017;12:49.

69. Balogun OO, Dagvadorj A, Anigo KM, Ota E, Sasaki S. Factors influencing breastfeeding exclusivity during the first 6 months of life in developing countries: a quantitative and qualitative systematic review. Matern Child Nutr. 2015;11(4):433-51.

70. Strang L, Broeks M. Maternity leave policies. Rand Health Q. 2017;6(4):9.

71. Thulier D, Mercer J. Variables associated with breastfeeding duration. J Obstet Gynecol Neonatal Nurs. 2009;38(3):259-68.

72. Golian Tehrani S, Bazzazian S, Dehghan NN. Pregnancy experiences of firsttime fathers in Iran: a qualitative interview study. Iran Red Crescent Med J. 2015;17(2):e12271

73. Radwan H. Patterns and determinants of breastfeeding and complementary feeding practices of Emirati mothers in the United Arab Emirates. BMC Pub Health. 2013;13:17

74. Setegn T, Belachew T, Gerbaba M, Deribe K, Deribew A, Biadgilign S. Factors associated with exclusive breastfeeding practices among mothers in Goba district, south East Ethiopia: a cross-sectional study. Int Breastfeed J. 2012; 7(1):17.

75. Acharya $P$, Khanal $V$. The effect of mother's educational status on early initiation of breastfeeding: further analysis of three consecutive Nepal demographic and health surveys. BMC Public Health. 2015;15:1069.
76. Skouteris $H$, Nagle C, Fowler M, Kent B, Sahota P, Morris H. Interventions designed to promote exclusive breastfeeding in high-income countries: a systematic review. Breastfeed Med. 2014;9(3):113-27.

77. Jara-Palacios MÁ, Cornejo AC, Peláez GA, Verdesoto J, Galvis AA. Prevalence and determinants of exclusive breastfeeding among adolescent mothers from Quito, Ecuador: a cross-sectional study. Int Breastfeed J. 2015;10:33.

78. Alzaheb RA. Factors influencing exclusive breastfeeding in Tabuk, Saudi Arabia. Clin Med Insights Pediatr. 2017;11:1-8.

79. Prior E, Santhakumaran S, Gale C, Philipps LH, Modi N, Hyde MJ. Breastfeeding after cesarean delivery: a systematic review and meta-analysis of world literature. Am J Clin Nutr. 2012;95(5):1113-35.

80. Wieczorek PM, Guest S, Balki M, Shah V, Carvalho JC. Breastfeeding success rate after vaginal delivery can be high despite the use of epidural fentanyl: an observational cohort study. Int J Obstet Anesth. 2010;19(3):273-7.

81. Regan J, Thompson A, DeFranco E. The influence of mode of delivery on breastfeeding initiation in women with a Prior cesarean delivery: a population-based study. Breastfeed Med. 2013;8(2):181-6.

82. Azami-aghdash S, Ghojazadeh M, Dehdilani N, Mohammadi M, Asl Amin Abad R. Prevalence and causes of cesarean section in Iran: systematic review and meta-analysis. Iran J Public Health. 2014;43(5):545-55.

83. Shahshahan Z, Heshmati B, Akbari M, Sabet F. Caesarean section in Iran. Lancet. 2016:388(10039):29-30.

84. Olyaeemanesh A, Behzadifar M, Mousavinejhad N, Behzadifar M, Heydarvand S, Azari S, et al. Iran's health system transformation plan: a SWOT analysis. Med J Islam Repub Iran. 2018;32(1):1-7.

85. Tampah-Naah AM, Kumi-Kyereme A. Determinants of exclusive breastfeeding among mothers in Ghana: a cross-sectional study. Int Breastfeed J. 2013;8(1):13.

86. Singh D, Devi N, Raman TR. Exclusive breast feeding in low birth weight babies. Med J Armed Forces India. 2009;65(3):208-12.

87. Mamemoto K, Kubota M, Nagai A, Takahashi Y, Kamamoto T, Minowa H, et al. Factors associated with exclusive breastfeeding in low birth weight infants at NICU discharge and the start of complementary feeding. Asia Pac J Clin Nutr. 2013;22(2):270-5.

88. Islam M, Rahman S, Kamruzzaman IM, Samad A. Effect of maternal status and breastfeeding practices on infant nutritional status - a cross sectional study in the south-west region of Bangladesh. Pan Afr Med J. 2013;16:139.

\section{Publisher's Note}

Springer Nature remains neutral with regard to jurisdictional claims in published maps and institutional affiliations.

Ready to submit your research? Choose BMC and benefit from:

- fast, convenient online submission

- thorough peer review by experienced researchers in your field

- rapid publication on acceptance

- support for research data, including large and complex data types

- gold Open Access which fosters wider collaboration and increased citations

- maximum visibility for your research: over $100 \mathrm{M}$ website views per year

At BMC, research is always in progress.

Learn more biomedcentral.com/submissions 